\title{
Review on Features and Incentives of Food Safety Crisis
}

\author{
Xu Zu ${ }^{1, *}$, Weiping Yu ${ }^{2}$, Yue Qiu ${ }^{3}$ \\ ${ }^{1}$ Business School, Si Chuan Agricultural University, Chengdu, 611830; \\ ${ }^{2}$ Business School, Si Chuan University, Chengdu, 610065 \\ ${ }^{3}$ Graduate School, Chengdu University of TCM, Chengdu, 611137
}

Keywords: Food Safety Crisis, Features, Incentives

\begin{abstract}
This paper introduces the importance of food safety crisis characteristics and incentive research results through realistic background. From the macro perspective, general attribute characteristics, unique product attributes of food focus, food safety crisis characteristics and consumer response mechanism, the research results of food safety crisis characteristics are summarized. Based on attribution theory, around the government, enterprises and consumers, the research on the causes of the crisis in the three major aspects of the three parties is sorted out. Finally, it is found that there are multiple perspectives for the existing research results to comprehensively explore the insufficient characteristics of food safety crisis and explore the food safety crisis based on multi-view system.
\end{abstract}

\section{Introduction}

Food safety is both a major livelihood issue and a major political issue. However, food safety crises still occur frequently, such as the 2015 "Nitrate and Selenium Exceeding Standards" event in Guanshan Dairy, the "Cadmium Rice” incident, the "Standard Gate” incident at Nongfu Spring, and the reappearance of the new "Ground Oil" in 2016. It is not uncommon for people to talk about it, more than the degree of "talking about food change." The 2017 government work report once again mentioned the inclusion of food safety in the work of improving people's livelihood. Under the mobile Internet, information dissemination presents diversified channels and speed index, which makes food safety risks more likely to evolve into crises, posing a huge threat to food companies. Based on the realistic background, this study combines scholars' research on the relevant research results of food safety crisis characteristics and incentives to clarify existing research results and discover research opportunities, thus helping scholars to form richer food safety crisis characteristics and incentives. The research results provide powerful theoretical support and reference for food enterprises in formulating crisis management strategies.

\section{The characteristics of food safety crisis}

At present, the academic community has formed certain research results on the characteristics of food safety crisis. Specifically, it can be summarized into four aspects: (1) Studying the characteristics of food safety crisis based on macroscopic perspectives, such as Tang Wei, Li Danting (2008), exploring the characteristics of the whole process of food safety problems in China, the multi-subjects dereliction of duty and the multi-factor influence in the development process. In order to prevent food safety risks and respond to food safety crisis, we provide targeted governance paths. Wen Xiaolan, Liu Miaoling (2012) based on the case study of food safety crisis in China from 2002 to 2011, found that food operators "know the crime" is a food safety problem. The key causes of this, while clarifying the initial processing of agricultural products, food deep processing, sales/catering from the supply chain link is the weak link of food safety, in which food deep processing forms the crisis with the greatest degree of harm, Zhang Hongxia, An Yufa (2014) from the cause of the crisis, the characteristics of the food safety crisis are analyzed in four aspects: the company involved in the enterprise, the exposure channel, and the source of exposure. (2) Focusing 
on the general product injury crisis event, using food as a stimulus item to study the general attribute characteristics of the crisis, which involves seriousness and correlation. Basic attribute characteristics such as sex and responsibility (Coo Mbs, 2007; Duan Guimin, Yu Weiping, 2012; Zhuang Ailing, Yu Weiping, 2014); (3) Focus on the unique product attributes of food, and study its negative externalities or negative spillovers from the characteristics of food safety crisis hazards and correlations (Wu Yuanyuan , 2012; Gong Qiang et al., 2013; Zhuang Ailing, Yu Weiping, 2014; Cui Baojun, 2015); (4) Combining the typical food safety crisis in China, in-depth study of the characteristics of China's group hair food safety crisis and the mechanism of consumer response, such as Ren Jinzhong And Jing Fengjie (2012, 2013) based on the crisis of food safety in the beverage industry to explore consumer complaints and purchase intentions, Cui Baojun, Yu Weiping (2015) found that the industry's unspoken regular food safety crisis is coercive, deliberate, and serious crisis The failure characteristics of sexuality and regulatory system, and the reasons for consumer helplessness and masturbation and the targeted solutions.

\section{The food safety crisis incentives}

Based on the attribution theory, domestic and foreign scholars mainly focus on the crisis inducement research in three aspects: government, enterprises and third parties and consumers.

In terms of government incentives, scholars mainly focus on the imperfect government supervision system and the lack of work of supervisors. Martinez \& Fearne et al (2007) believe that the effective operation of the food market is inseparable from efficient food safety regulation. In the 1990s, the regulatory failure of food safety in the UK and EU relevant government regulatory authorities caused the outbreak of the "mad cow disease" food safety crisis. The main incentive. Regulatory authorities' own resource constraints also prevent regulators from fully monitoring every link and product in the food supply chain (Crespi \& Marette, 2001; Lapan \& Moschini, 2007), Wen Xiaolan, Liu Miaoling (2012) found food safety crisis The occurrence of this is closely related to the government's regulatory system and supervisors. Due to the lag of the level of food testing supervision and the lack of awareness of food-borne pathogens by regulators, it is prone to involuntary negligence, which will result in the inferior food being undiscovered and entering the consumption chain. In addition to the imperfect laws and regulations on food safety and tracking penalties, the hazards of food safety incidents continue to escalate. Huo Youguang, Yu Huili (2015) found that the relevant legal system was missing from the food safety crisis of small and micro enterprises, and the early warning was insufficient. The role played by the government is the main factor in the food safety crisis. Cui Baojun, Yu Weiping (2015) found that the lack of government supervision and the lack of social power to participate in governance from the industry's unspoken food safety crisis are food safety issues. Existence and crisis The main incentives, Xiao Pinghui, Qi Zhigang (2007) and Khalid (2016) also found that food standards are imperfect, the basis for judgment is incorrect, and the inconsistency between administrative departments is one of the main causes of food safety problems and food safety crisis.

In terms of corporate incentives, scholars mainly study the causes of food safety crisis in two aspects: business capability and business ethics. Information asymmetry between enterprises and consumers is likely to lead to food safety problems (Ortega, Wang et al., 2011). The existence of such safety problems is likely to induce food safety crisis. Zhou Yingheng, Wang Erpeng (2013) will solve the problem of modern food safety crisis. The incentives are summarized into two categories: ignorance and unscrupulity. The ignorance is related to the ability of the enterprise, that is, the uncertainty caused by the adoption of new technologies and new processes; the unscrupulous is related to business ethics, that is, in the process of food production and manufacturing, the actor Driven by interests and contrary to the ethics of integrity, malicious food safety issues, such as Sanlu "melamine milk powder" incident. In terms of corporate capabilities, Zhang Hongxia and an Yufa (2014) concluded that production accidents caused by unqualified raw materials or suppliers, unqualified production conditions or mistakes, and improper sales and poor management of enterprises are likely to induce food safety crisis. Lamuka (2014) In the study of food safety governance in developing countries, it is found that the irregular operation and poor management of 
enterprises will lead to frequent food safety problems and pose great challenges to food safety management. Motarjemi (2014) also mentioned that human error is one of the incentives for food safety crisis. In terms of business ethics, because food safety has the property of trust (Antle, 2001), excessive use of pesticides, abuse of additives, illegal addition of other chemical substances, selection of expired food raw materials and illegal operation of food processing personnel, etc. Existence (Wen Xiaotong, Liu Miaoling, 2012), Wang Changwei, Gu Haiying (2013) In view of the attribute of trust and information asymmetry, the lack of corporate integrity will lead to the food safety problem in China. Cui Baojun, Yu Weiping (2015) believes that brand enterprises Integrity Demonstration effect of the loss of unscrupulous producers and operators of high profit-driven motivation will lead to mass phenomenon of moral hazard in the food industry, which are frequent industry rule-type food safety crises.

In terms of third-party and consumer incentives, scholars believe that media misunderstanding and one-sided publicity, and lack of awareness of news media will fuel the food safety crisis (Xiong Xianlan, 2014; Zhang Hongxia, An Yufa, 2014; Han Zhen, Qi Liyun, etc., 2015), Insufficient participation in the food industry association will further fuel the food safety crisis (Xiong Xianlan, 2014). Consumers are mainly reflected in the lack of food safety crisis awareness (Chen Lesong, 2013), distrust and misunderstanding of enterprises, thus affecting consumers' food safety. Attitudes and behaviors (Zhao Yuan, Tang Jiansheng et al., 2012).

\section{Research review and entry point of this study}

From the literature review, the theoretical and practical significance of the field of food safety research has been widely recognized by scholars at home and abroad. However, from the literature review, it can be seen that the systematic research on the characteristics and incentives of food safety crisis is insufficient. There are still research opportunities (such as Table 1) for the research on the characteristics of the crisis and the incentives to further summarize the factors affecting consumer trust (see Table 1).

\subsection{A comprehensive perspective on the characteristics of the food safety crisis}

Although the characteristics of the food safety crisis have formed certain research results, the general characteristics of the food safety crisis are explored from the macro perspective, the food as the stimulating goods category, the unique product attributes of the focused food and the group food safety crisis. There are still research opportunities: First, starting from the focus of research, scholars in the past often combine the research topics to develop specific scenarios of food safety crisis characteristics, and explore the local characteristics of food safety crisis from a micro perspective. Systematic research on the characteristics of food safety crisis; Secondly, from the macroscopic perspective, qualitative research methods are mainly used to subjectively extract the characteristics of food safety crisis, and there are expressions that confuse characteristics with incentives, such as Wen Xiaolan, Liu Miaoling ( 2012) Taking the "knowing and guilty" of food operators as one of the characteristics of food safety crisis, it is not able to clarify the characteristics and incentive factors of food safety crisis. Third, with the management of food safety crisis by enterprises, governments and other subjects. Attention and mobile internet, internet of things and the development of intelligence, the characteristics of food safety crisis will have new characteristics, and still need to systematically study the characteristics of food safety crisis under mobile internet, and systematically analyze the case of food safety crisis to improve the effectiveness of food enterprises. Crisis governance is necessary.

\subsection{There are fewer incentives to explore food safety crisis based on multi-view systems}

It can be seen from the literature review that when domestic and foreign scholars study food safety governance or explore the negative effects or spillover mechanism of food safety crisis, the incentives related to food safety crisis are the factors of general concern. However, from the perspective of research methods, the existing research results are mostly subjectively summarized in the government's weak supervision and lack of corporate integrity. There is no combination of 
quantitative and qualitative research methods based on typical cases to explore the causes of crisis, and the research depth needs to be strengthened; From the research content, the existing research results are mostly fragmented, or summarize the crisis incentive categories of stakeholders such as government, enterprises, third parties and consumers from a macro level (Lamuka, 2014; Motarjemi, 2014), or involve a certain A specific crisis inducement related to consumer behavior and brand equity (Zhuang Ailing, Yu Weiping, 2014), can not systematically describe the food safety crisis incentives; from a research perspective, the existing research results are concentrated on typical foods The case study of food safety crisis incentives, research perspective is relatively simple, has not yet deepened the crisis incentives from the perspective of multi-agent comparisons of government, enterprises and consumers.

Table 1 Related research opportunities

\begin{tabular}{|c|c|c|}
\hline C & Existing research & Research opportunity \\
\hline Crisis characteristics & $\begin{array}{l}\text { - Summary of } \square \text { general } \\
\text { characteristics based on macro } \\
\text { perspective: loss of the whole } \\
\text { process, failure of multiple subjects, } \\
\text { etc.; } \\
\text { - General characteristics of food } \\
\text { research as a stimulus item: } \\
\text { seriousness, responsibility, etc.; } \\
\text { - Focus on the unique product } \\
\text { attributes of food and study the } \\
\text { negative externalities or negative } \\
\text { spillover effects of the crisis; } \\
\text { - In-depth study of unique } \\
\text { characteristics in the context of } \\
\text { group hair food safety crisis }\end{array}$ & $\begin{array}{l}\text { - A qualitative and systematic } \\
\text { interpretation of the characteristics } \\
\text { of the crisis under the mobile } \\
\text { Internet with subjective inductive } \\
\text { qualitative research and a single } \\
\text { perspective of fragmentation }\end{array}$ \\
\hline Crisis of crisis & $\begin{array}{l}\text { Incentives from the } \\
\text { government perspective: imperfect } \\
\text { food standards, incorrect judgments, } \\
\text { and inconsistencies among } \\
\text { administrative departments; } \\
\square \quad \text { Corporate perspective } \\
\text { incentives: new technologies, new } \\
\text { process risks, human error, etc. } \\
\square \quad \text { Third-party perspective } \\
\text { incentives: } \\
\text { misunderstanding, media } \\
\text { publicity, etc.; } \\
\square \text { Consumers' perspectives: lack } \\
\text { of awareness of food safety crisis, } \\
\text { distrust of enterprises, etc.; }\end{array}$ & $\begin{array}{l}\text { - Research methods are mainly } \\
\text { subjective induction. The research } \\
\text { content is mostly from the macro } \\
\text { level or focusing on a certain } \\
\text { incentive research. The research } \\
\text { perspectives are mostly based on a } \\
\text { single case of typical cases. The } \\
\text { research results formed cannot } \\
\text { comprehensively and systematically } \\
\text { summarize the crisis incentives } \\
\text { under mobile internet. Explain the } \\
\text { evolution process }\end{array}$ \\
\hline
\end{tabular}

\section{Acknowledgements}

Fund Project: Fund Project: Key Research Base of Philosophy and Social Science of Sichuan Province--Southwestern Poverty Reduction and Development Research Center Key Project (SCP1802); Sichuan Agricultural University Social Science Key Project (2018ZD04); Sichuan Province Philosophy and Social Science Key Research Base--Sichuan Agriculture Featured Brand Development and Communication Research Center General Project (CAB1810)

\section{References}

[1] Antle J M. Economic analysis of food safety [J]. Handbook of agricultural economics, 2001, 1: 1083-1136. 
[2] Chen Lesong. Domestic food safety crisis events and their impact [D]. Northeast Normal University, 2013.

[3] Chen Shifa, Chen Yaxian. A Review of the Status Quo of Legal Documents and the Construction of Legal System in Jinyu and Luyu Bases[J]. Theoretical Journal, 2013(8).

[4] Coombs W T. Protecting Organization Reputations During a Crisis: The Development and Application of Situational Crisis Communication Theory [J]. Corporate Reputation Review, 2007, 10(3): 163-176.

[5] Crespi J M, Marette S. How Should Food Safety Certification be Financed? [J]. American Journal of Agricultural Economics, 2001, 83(4): 852-861.

[6] Cui Baojun, Yu Weiping. Characteristics, Causes and Governance of Industry Unspoken Regular Product Injury Crisis_—_Taking the Food Industry as an Example[J]. Social Science Front, 2015(8): 44-53.

[7] Cui Baojun. Social harm of product injury crisis in food industry and renewal of government governance mechanism[J]. Journal of East China University of Science and Technology(Social Science Edition), 2015, 30(1): 37-47.

[8] Duan Guimin, Yu Weiping. Research on the Impact of Sub-brand Injury Crisis on the Evaluation of Main Brands__-Intermediary Role of Consumers' Negative Emotions[J]. East China Economic Management, 2012, 26(4): 115-119.

[9] Han Zhen, Qi Liyun, Zhang Hongwei. Research on Food Safety Based on Consumer Responsibility Cognition[J]. Journal of Dalian University of Technology, Social Science Edition, 2015(2): 13-19.

[10] Huo Youguang, Yu Huili. Food Safety Issues, Characteristics, Causes and Countermeasures of Small and Micro Enterprises[J]. Journal of Northwest A\&F University, Social Science Edition, 2015(6): 100-107.

[11] Lamuka P O. Public Health Measures: Challenges of Developing Countries in Management of Food Safety [J]. Encyclopedia of Food Safety, 2014: 20-26.

[12] Lapan H, Moschini G C. Grading, Minimum Quality Standards, and the Labeling of Genetically Modified Products [J]. American Journal of Agricultural Economics, 2007, 89(3): 1222-1229.

[13] Gong Qiang, Zhang Yilin, Yu Jianyu. Incentive, Information and Food Safety Regulation[J]. Economic Research, 2013(3): 135-147.

[14] Martinez MG, Fearne A, Caswell JA, et al. Co-regulation as a possible model for food safety governance: Opportunities for public-private partnerships[J]. Food Policy, 2007, 32(3): 299-314.

[15] Motarjemi Y. Food Safety Assurance Systems: Essentials of Crisis Management [J]. Encyclopedia of Food Safety, 2014: 322-330.

[16] Ortega D L, Wang H H, Wu L, et al. Modeling heterogeneity in consumer preferences for select food safety attributes in China [J]. Food Policy, 2011, 36(2): 318-324.

[17] Ren Jinzhong, Jing Fengjie. The Impact of Enterprise and Industry Crisis on Consumers' Intentions in the Case of Product Injury Crisis[J]. Economic Management, 2013 (4): 94-104.

[18] Ren Jinzhong, Jing Fengjie. The Mechanism of Self-consistent Attribution and Behavioral Intention in the Fuzzy Situation of Product Injury Crisis[J]. Journal of Marketing Science, 2012, 8(3): 88-106.

[19] Tang Wei, Li Danting. Food Safety Management in China: Characteristics, Roots and Policy Suggestions [J]. Exploration, 2008(6): 74-78. 
[20] Wang Changwei, Gu Haiying. Industrial Environment, Supervision and the Integrity Choice of China's Food Enterprises_—Based on the Analysis of Incentive Compatibility Constraints[J]. Business Economics and Management, 2013(8):18-25.

[21] Wen Xiaotong, Liu Miaoling. Inducement, Dilemma and Supervision of Food Safety: 2002-2011[J]. Reform, 2012(9): 37-42. 